\title{
Developing cognitive ecosystem model of cryptocurrency
}

\author{
Mohammad Reza Taghva ${ }^{1^{*}}$ iD , Zahra Jalaeian Zaferani \\ 1. Assistant Professor of Computer Engineering, Management and Accounting Faculty, Allameh Tabataba'i University, Tehran, Iran \\ 2. PhD Student of Information Technology Management, Management and Accounting Faculty, Allameh Tabataba'i University, Tehran, Iran
}

Recieved: 15 Aug. 2019

Revised: 16 Dec. 2019

Accepted: 28 Dec. 2019

\section{Keywords \\ Ecosystem \\ Cognitive ecosystem \\ Cryptocurrency \\ Bitcoin}

\section{Corresponding author}

Mohammad Reza Taghva, Assistant Professor of Computer Engineering, Dehkadeh Olympic, Varzesh Sq, Central Building of Allameh Tabataba'i University, Tehran, Iran

Email: Taghva@gmail.com

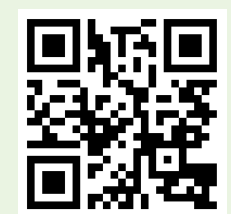

\section{Abstract}

Introduction: The advancement of cognitive science in a field common to computer science is becoming one of the crucial ways to advance social, economic, technical, and computer science. Meanwhile, debates over the cryptocurrency and its ecosystem as a thing which is capable of transferring value across cyberspace have been evolving over the past decade. In contrast, the impact of cognitive science on the electronicization of life is evident. Today's innovations are developed by the semantic and cognitive interpretation components and characteristics of the human mind that work on the relationships between the real and the virtual world. Cryptocurrency, as an innovative phenomenon needs to be developed by the human mind's semantic and cognitive interpretation components and characteristics.

Methods: according to the "Cognitive Banking Ecosystem" model developed by IBM in 2016 in five layers (core, key activities, capabilities, infrastructure, and tools). The present study uses the Strauss and Corbin version of the Grounded Theory to systematically analyze social processes in order to extract elements in each layer according to the exploratory nature of the research.

Results: The final model consists of the five main layers mentioned above and 24 elements that were approved by submitting a researcher-made questionnaire to the experts.

Conclusion: Since previous researches have focused on some part of the cryptocurrency ecosystem, the present study attempted to create a whole understanding of the cognitive coding ecosystem and to fill in the knowledge gap.

Citation: Taghva M, Jalaeian Zaferani Z. Developing cognitive ecosystem model of cryptocurrency. Advances in Cognitive Sciences. 2020;22(2):102-110. 


\author{
توسعه مدل اكوسيستم شناختى رمزارز \\ محمد رضا تقوا"* (D) ، زهرا جلاييان زعفرانى؟
}

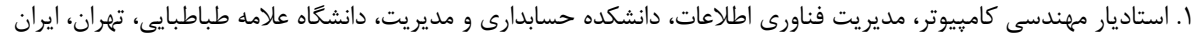

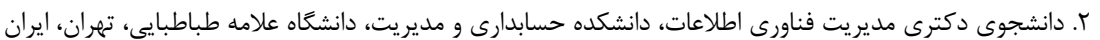

\title{
ars
}

مقدمهه: پيشرفت علوم شناختى در حوزهاى مشترك با علوم رايانه، در حال تبديل شدن به يكى از راههاى مههم پِيشرفت علوم اجتماءى، اقتصادى، فنى و رايانهاى است. در همين حين طى دهه كذشته مباحث مرتبط با رمزارز و اكوسيسته آن به عنوان شىاى كه قابليت انتقال ارزش را در سطح فضاى مجازى دارد، در حال توسعه پِيدا كردن است. در تقابل اين دو، تاثير علوم شناختى بر الكترونيكى شدن زندكى روزمره به عنوان عاملى تعيين كننده براى آن كاملا مشهود است. نوآورىهاى امروزه توسط اجزاى تفسير معنايى، شناختى و ويزگى هاى مشخصه ذهن انسان كه بر روى روابط بين دنياى واقعى و مجازى كار مى كنند، توسعه داده مىشوند. رمزارز نيز به عنوان يك يديده نوآور، از اين مبحث مستثنى نيست و لازم است توسط اجزاى تفسير معنايى، شناختى و ويزگى هاى مشخصه ذهن انسان توسعه يابد. روش كار: با توجه به مدل (اكوسيستم شناختى بانكدارى" كه توسط شركت IBM در سال 19 .r در ه لايه (هسته اصلى، فعاليتهاى كليدى، قابليتها، زيرساخت و ابزار) طراحى شده است؛ اين مدل مبناى كار يروهش قرار داده شده و سيس به منظور استخراج عناصر در هر لايه با توجه به ماهيت اكتشافى يُوهش، از روش داده بنياد با نسخه Strauss و Corbin كه با تحليل نظاممند به كشف فرايندهاى اجتماعى مى يردازد، استفاده نموديم. يافته ها: مدل نهايى اكوسيستم شناختى رمزارز شامل پنج لايه اصلى و MF عنصر مى باشد كه با ارائه يرسشنامه محقق ساخته به خبركان، مورد تاييد قرار كرفت. نتيجه كَيرى: با توجه به آن كه يزوهشهاى ييشين به بخشى از اكوسيستم رمزارز يرداخته بودند، در يُوهش حاضر تلاش شد تادرك كلى از اكوسيستم شناختى رمزارز ايجاد شده و شكاف دانشى مذكور ير شود. لازم به ذكر است با توجه به جديد بودن موضوع رمزارز و احتمال تغيير در اكوسيستم فعلى، در آينده مطالعات گستردهترى دراين حوزه صورت يذيرد.

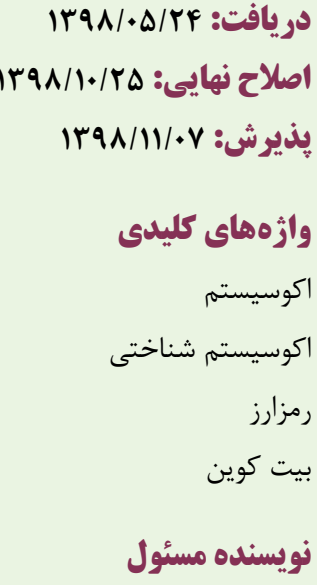

محمد رضا تقوا، استاديار مههندسى كامييوتر، دهكده الميّيك، ميدان ورزش، ساختمان مر كزى دانشكاه علامه طباطبائى، تهران، ايران ميدان

ايميل: Taghva@gmail.com

\section{口ifl \\ Prts 口回员立}

dol doi.org/10.30699/icss.22.2.102

مقدمبه

همه اجزاى اصلى در ساختمان آن بستخى دارد ( (1). اكولوزى شناختى مطالعه متنى گيديدههاى شناختى است كه به طور خاص اشاره به وابستكى متقابل وب به عناصر اكوسيستم شناختى دارد. بنابراين درك يديدهاى شناختى بايد شامل درك محيطهايى كه در آن فرايندهاى شناختى توسعه مى يابند و عمل مى كنند، باشد. صحبت كردن درباره
زمانى كه يك سازمان تشكيل روابط نظاممندى مى دهد، روابطى بين

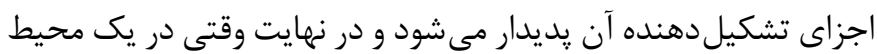
قرار مى گيرد، يك سيستم بزرگتر را شكل مى دهد. به دليل وجود روابط قانونمند و هدفدار بين محيط و سازمانها، اين مجموعه را در اصطلاح اكوسيستم مى نامند. استقرار پايدار هر اكوسيستم منحصراً به مشاركت 
هوش انسانى، \&) تعامل به شكل يك رفتار طبيعى مىباشد. نهايتاً

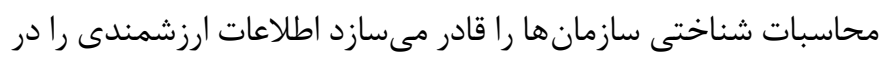

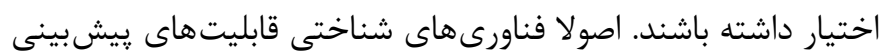
به موقع در زمان واقعى را ايجاد مى كنند.

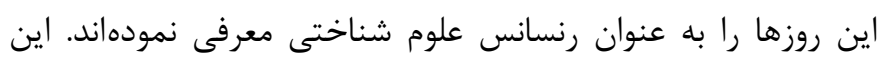

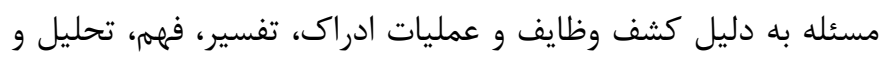

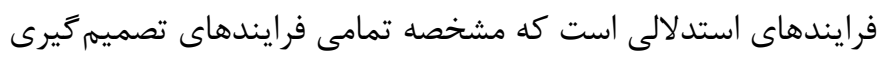
ذهن انسان مى باشد. اين فرايندها به همراه الكوريتمهاى توسعهيافته

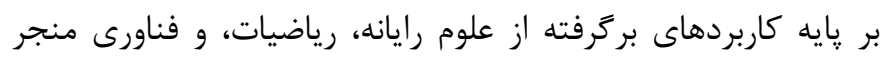

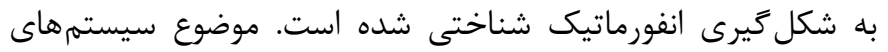

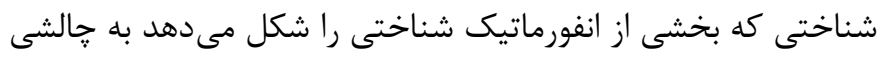

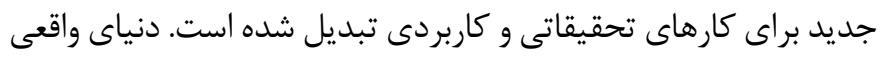

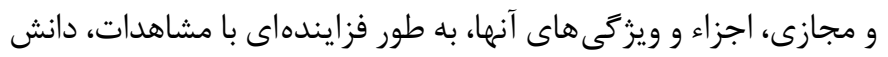

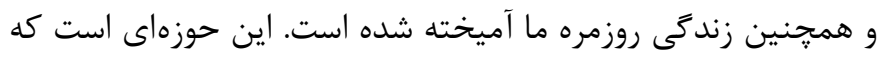

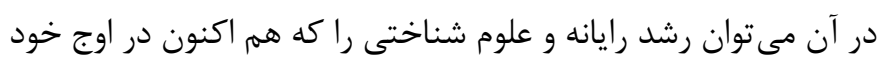

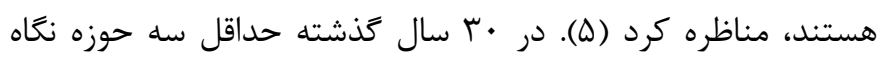

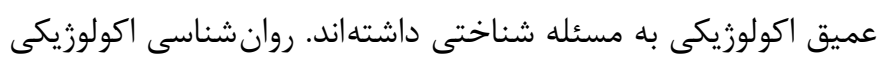
Gibson ، اكولوزى ذهن Bateson و نظريه فعاليت تاريخى_فرهنى

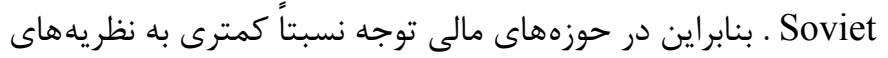

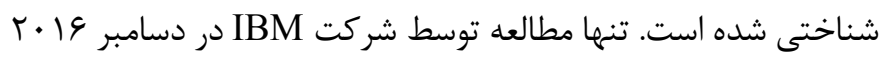
مىباشد كه اكوسيستم شناختى بانكدارى را ارائه نموده است (9) (ع).

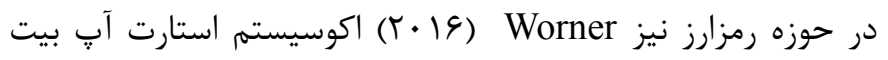

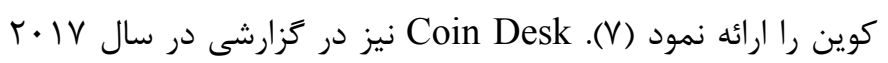

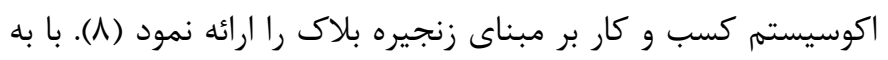

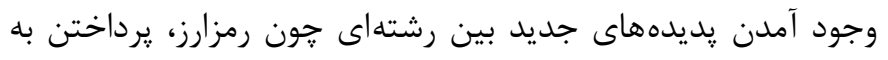
اكوسيستم شناختى اين بديده نوظهور حائز اهميت خواهد شد.

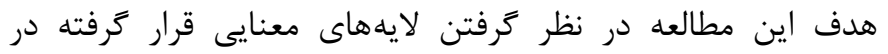

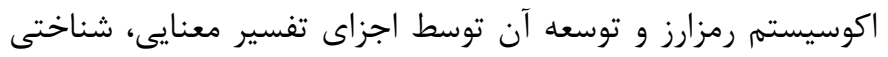
و ويزگى هاى مشخصه ذهن انسان مىباشد. اين موضوع علاوه بر

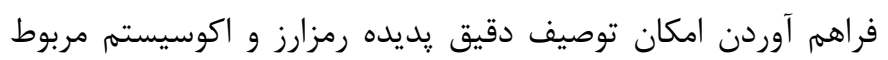

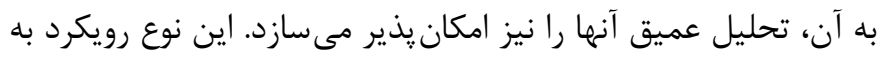

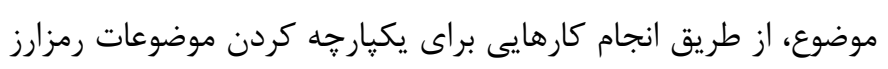

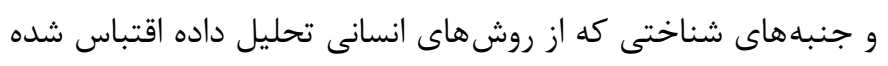

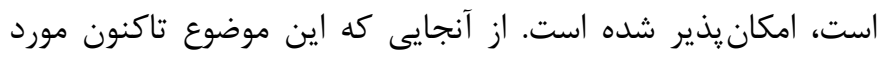

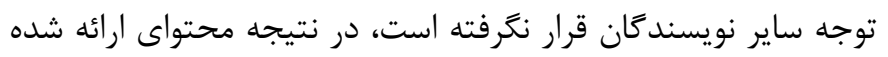

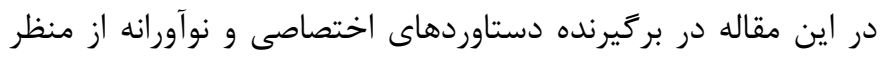

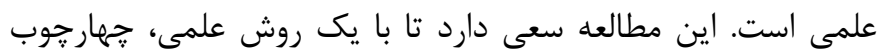

اكولوزى شناختى مثل اين استعاره است كه سيستههاى شناختى با

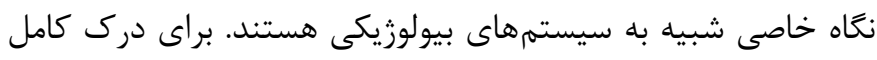

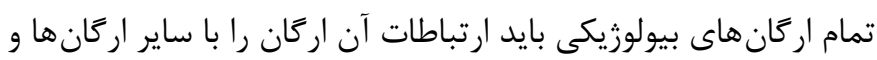

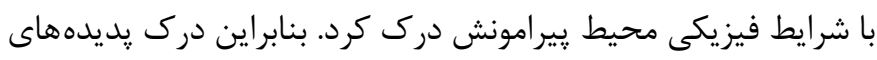

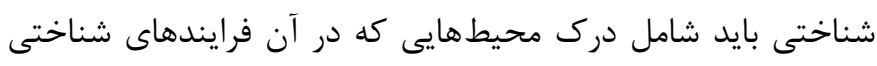

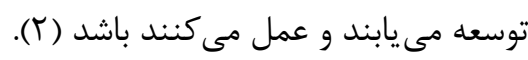

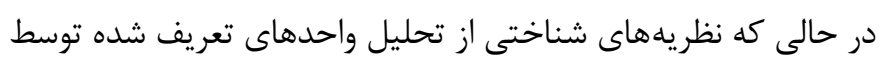

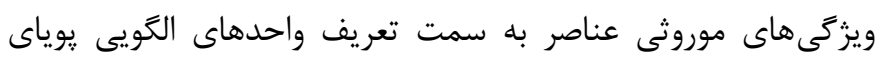
عناصر وابسته به هم تغيير مى يابد، مطالعه سيستمهاى شناختى اهميت روز افزونى در علوم شناختى ويدا مى كند. عناصر اكولوزى شناختى به

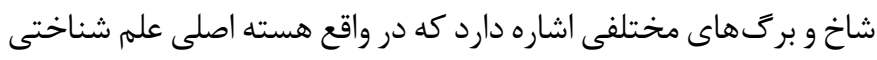

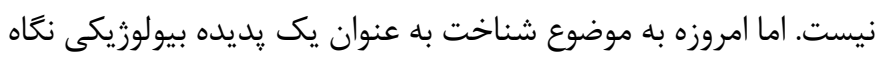

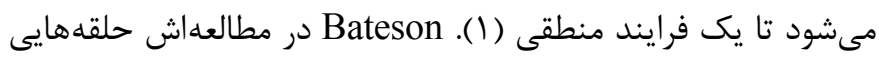

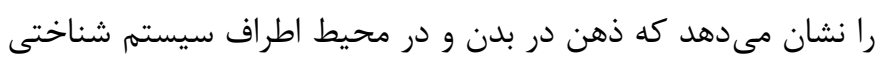

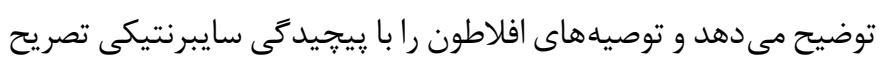

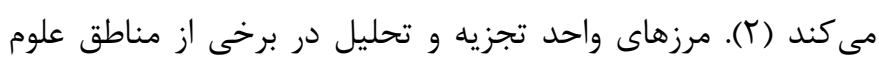

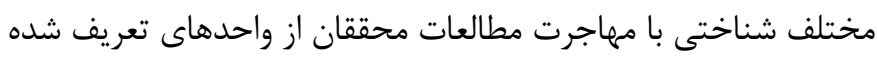

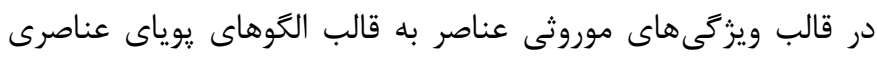
كه با هم همبستخى متقابل دارند، كسترش يافته است (ساص). اين دقيقاً

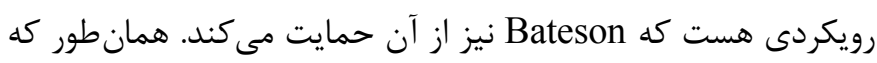

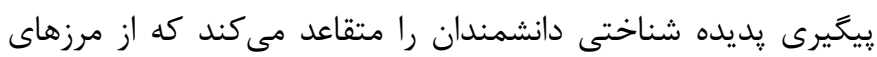

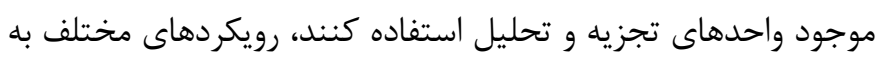

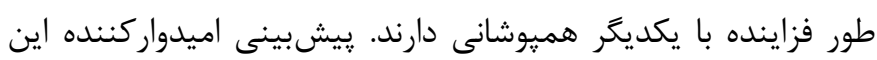

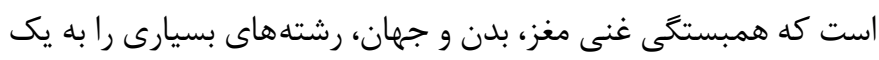

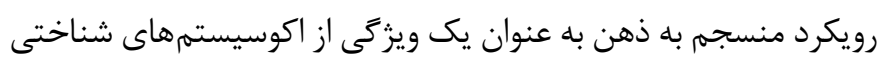

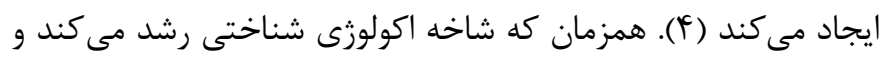

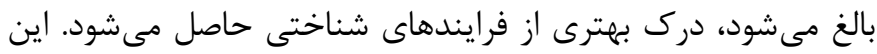

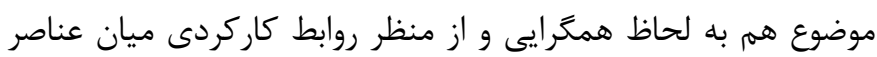

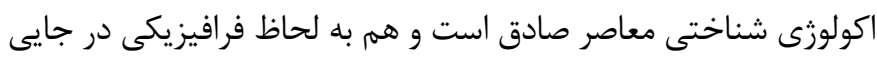
كه درى انقلاب شناختى است كاربرد دارد (\$). بر اساس كفتههاى IBM طى كزارش منتشر شده توسط فايننشال

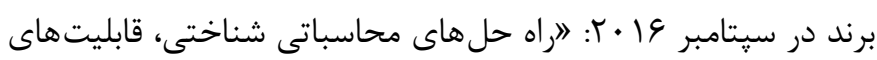

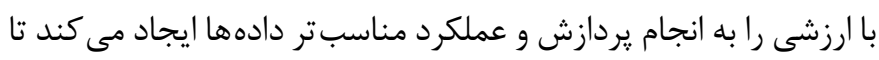

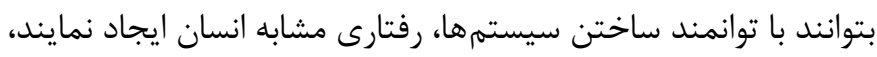

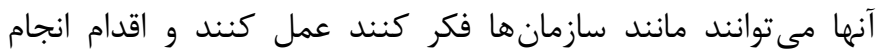
دهند". جهار اصلى كه زيرساخت محاسبات شناختى را ايجاد مى كند

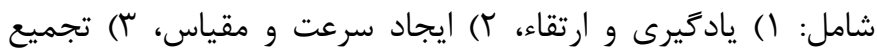


IBM در سال 9 • • ا ارائه شده است كه به عنوان مدل پايه مدنظر قرار داده شده است (شكل (). لايههاى اصلى آن (هسته، فعاليتهاى كليدى،

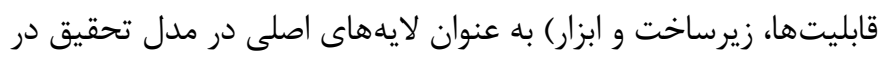

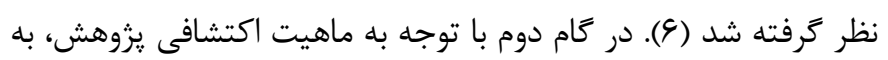

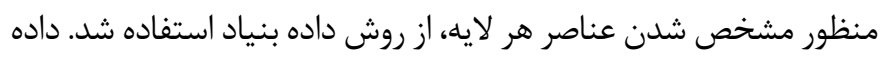

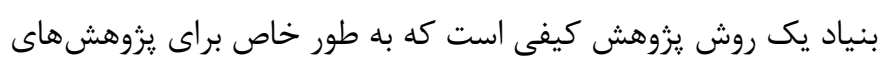

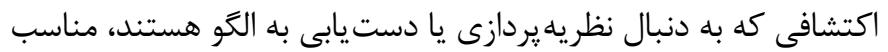

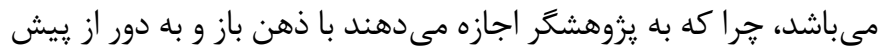
داورى يا فرضيه به كردآورى و تحيلى دادهها بيردازد (9).
مفهومى براى اكوسيستم شناختى رمزارز را توسعه دهد. هدف اصلى

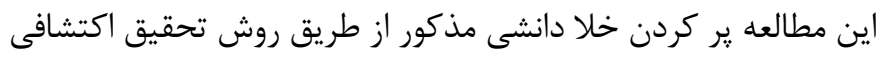

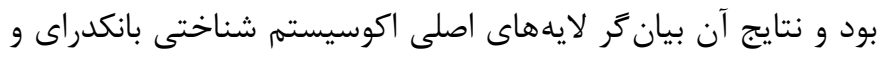
عناصر مربوط به هر لايه در حوزه اكوسيستم شناختى رمزارز بود. روش كار يزوهش حاضر از نوع يزوهش اكتشافى بود كه سعى در شناخت اكوسيستم شناختى رمزارز و توسعه مدل آن داشت. به اين منظور در كام اول با توجه به مدل اكوسيستم شناختى بانكدارى كه توسط شركت

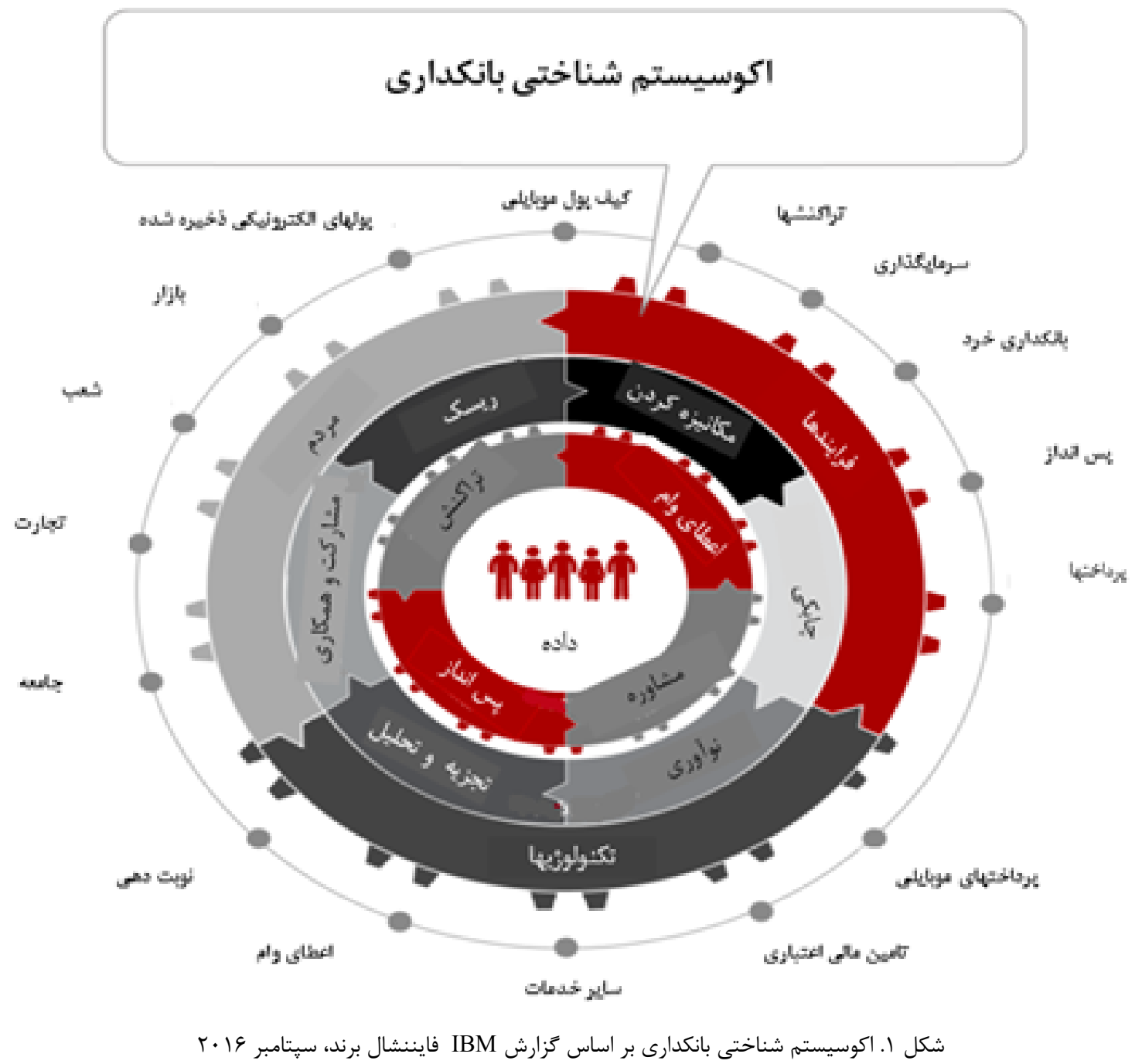

شديم ادامه يافت. در مجموع سا مصاحبه نيمه ساختاريافته انجام شد. كليه مصاحبه ها ضبط گرديد و در مجموع • V9 دقيقه مصاحبه انجام شد. مصاحبه شامل سوالات باز در ينج بخش (هسته مركزى اكوسيستم، فعاليتهاى كليدى، قالبيتها، زيرساخت و ابزار) انجام شد. همجنين براى تكميل دادهها و بررسى ابعاد مختلف موضوع مورد بررسى، علاوه
جامعه يزوهش، خبر ₹ان حوزه رمزارز در سال ^هץ| در تهران بودند.

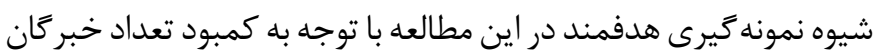
در اين استفاده شد. خبر Fان حوزه رمزارز، در خصوص شاخصهاى هر يك از لايههاى مدل اكوسيستم شناختى مورد يرسش قرار گرفتند. مصاحبهها تا نقطه اشباع يعنى تا هنًَامى كه با دادهاى تكرارى مواجه 
V V Vبقه، بخش ابزار V طبقه به دست آمد. براى اطمينان از روايى و

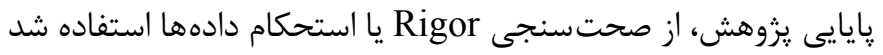

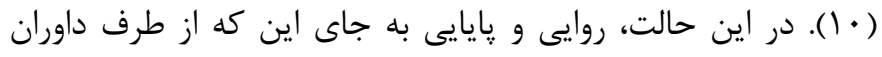

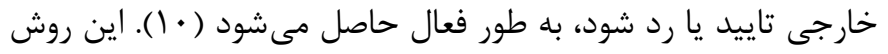

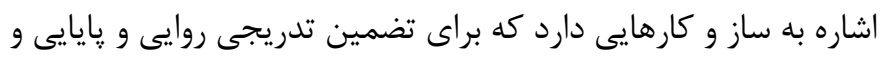
در نتيجه دقت علمى يزوهش در طى انجام تحقيق انجام مى شود (• (1). اين روش در همه مراحل اين مطالعه انجام كرفت تا با شناسايى و اصلاح خطاها قبل از ورود به مدل و قبل از اين كه تحليل را مخدوش مى سازد، نوعى يافته يزوهشى معتبر ايجاد كند. براى اين منظور تاكيد بر نوشتن

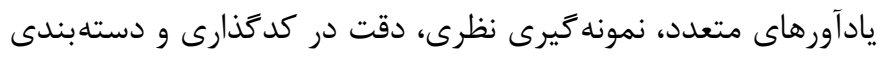

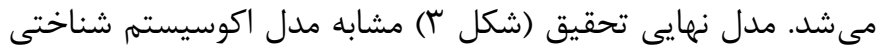

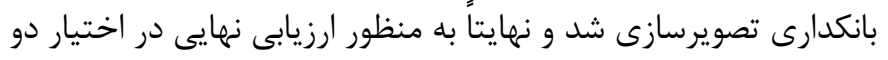
نفر خبركان قرار داده شد تا به تاييد نهايى برسد.
بر مصاحبه، از مشاهده مشاركتى نيز استفاده شد. براى تجزيه و تحليل دادهها براى هر يك از ينج بخش ذكر شده، از سه مرحله كدگذارى

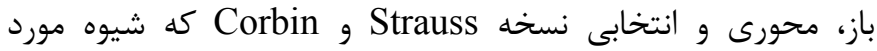
استفاده در روش داده بنياد مىباشد استفاده شده است (9). در مرحله كدَذارى باز، متن كليه مصاحبهها به صورت جداعانه مطالعه و مفاهيم و مقوله هاى آن استخراج شد. در مرحله كدكذارى محورى، مقوله ماى داى استخراج شده از مرحله قبل با يكديخر مقايسه شده و يكيارجه گَشتند. در مرحله كدكذارى انتخابى، مقولهها و ابعاد آنها مقايسه و يكيارجه

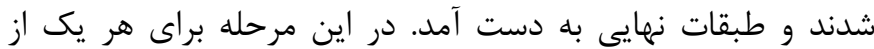
لايههاى اكوسيستم شناختى كه به عنوان انديشههاى اصلى در نظر

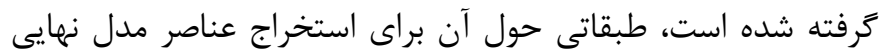

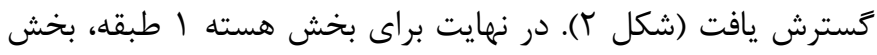
فعاليتهاى كليدى ه طبقه، بخش قابليتها ه طبقه، بخش زيرساخت
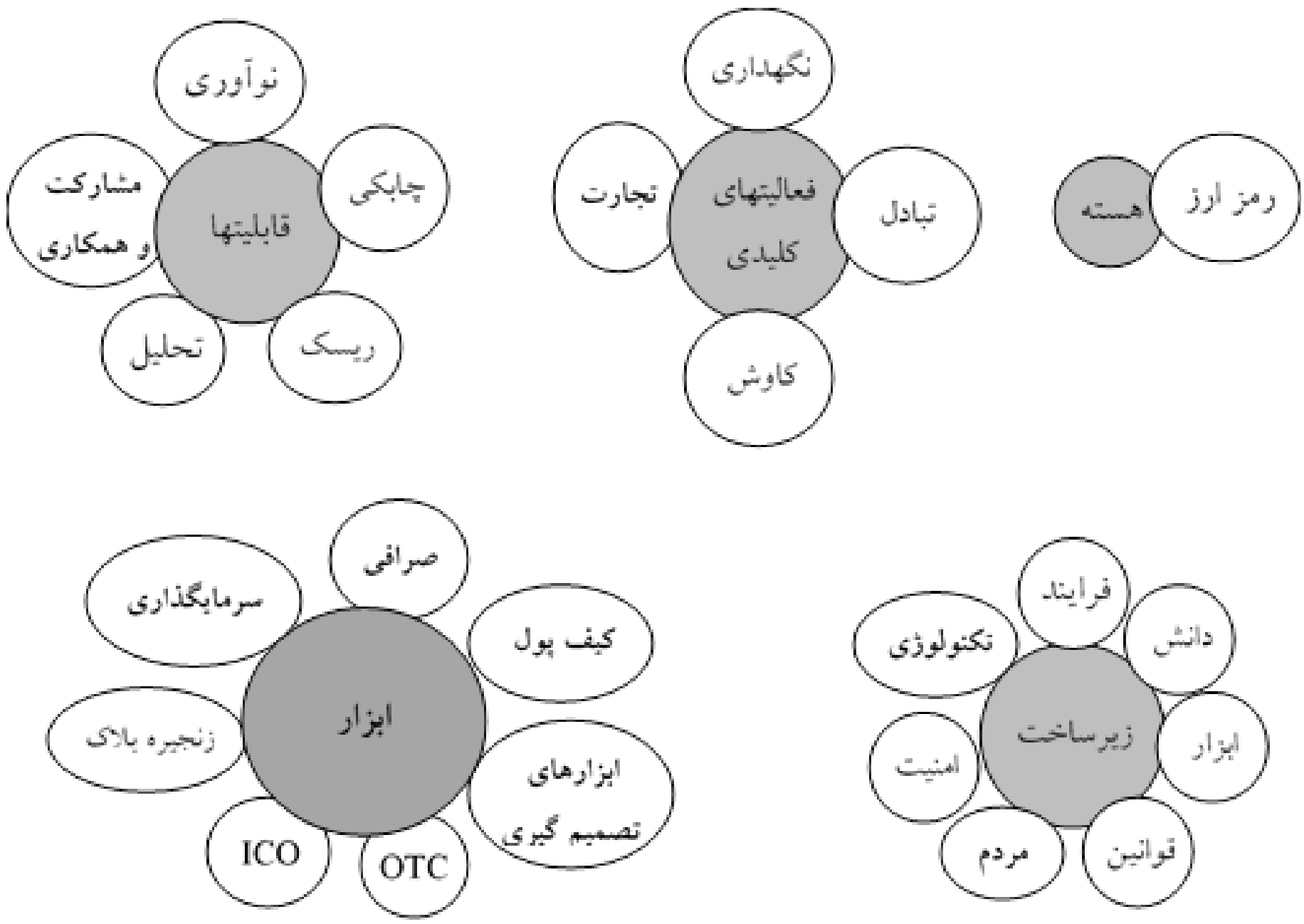


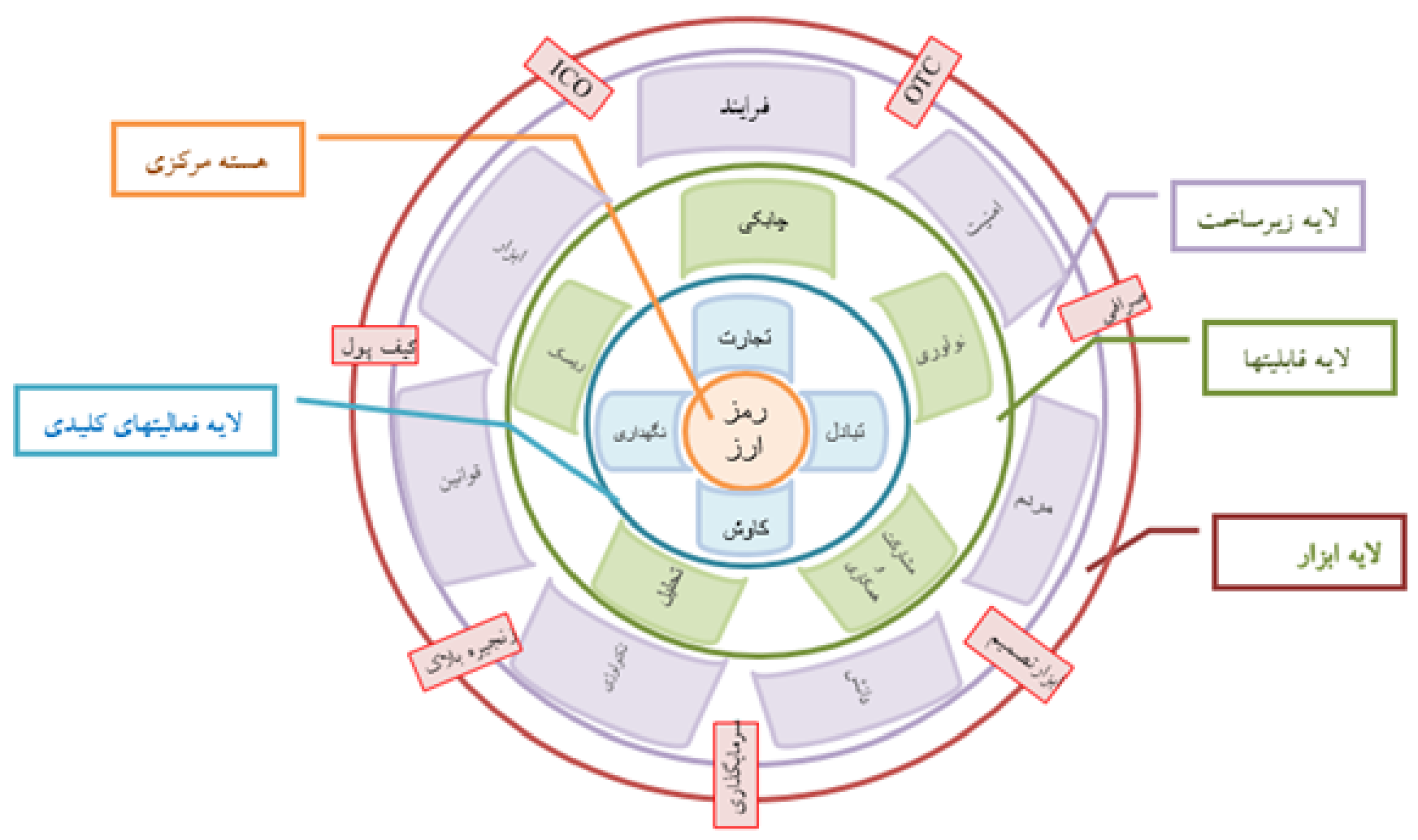

شكل ז. اكوسيستم شناختى رمزارز

يافته ها

است و باعث ايجاد اين اكوسيستم شده است.

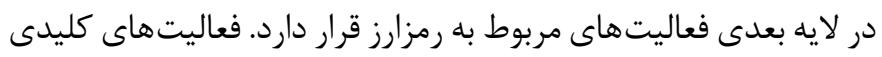

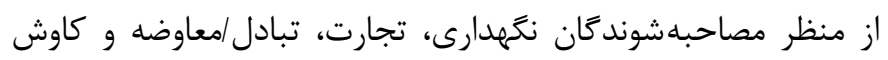

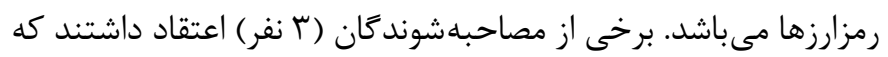

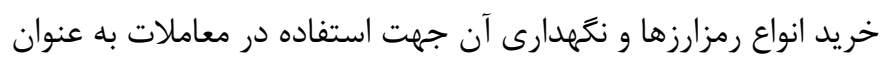

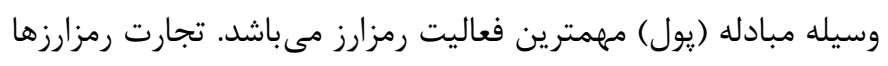

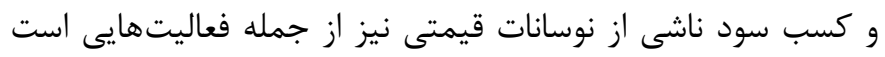

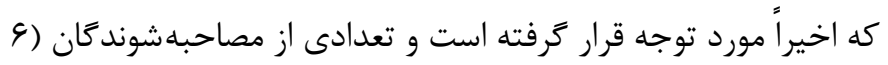

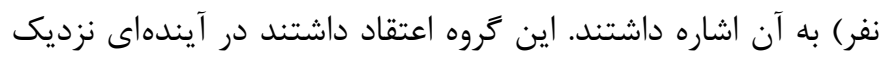

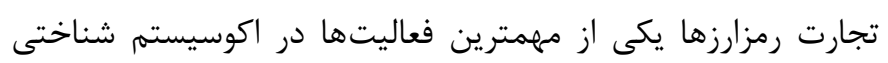
رمزارز خواهد بود. لايه بعدى قابليتها مى باشد. قابليتها شامل توانايى تحليل، نوآورى، رداد

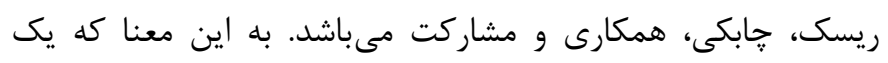

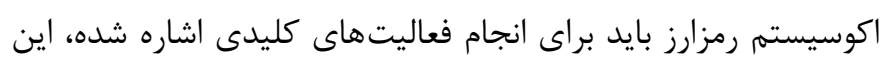

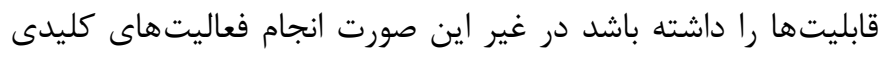

$$
\text { امكان يذير نخواهد بود. }
$$

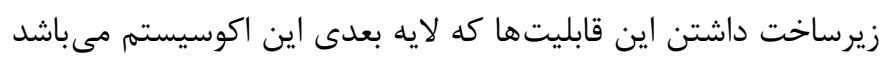

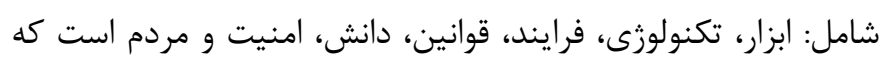

rا نفر از متخصصان رمزارز در مطالعه شركت نمودند كه همكى مرد

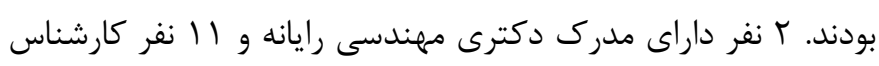

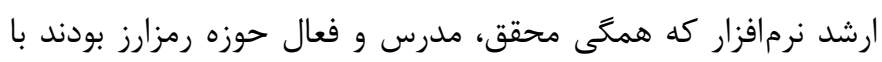

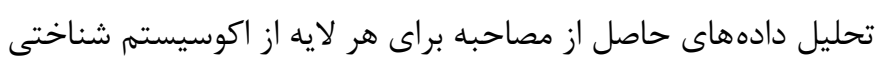

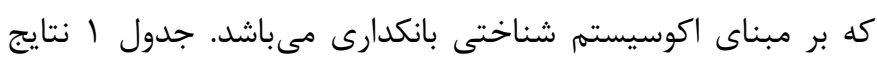
حاصل از كدَذارى را نمايش مى دهد.

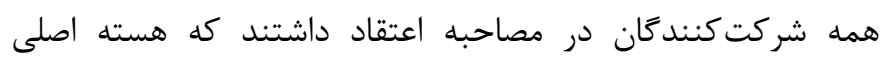

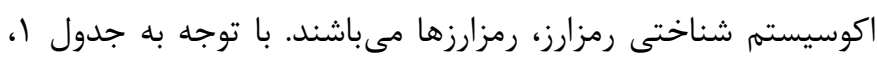
طبقات مفهومىاى به شرح زير حاصل شد. هسته اصلى: رمزارز؛

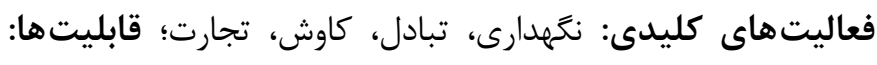

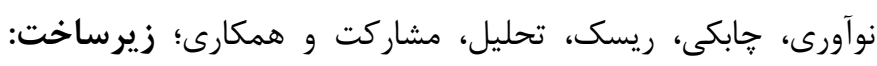

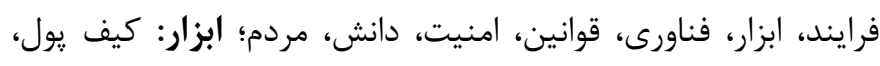

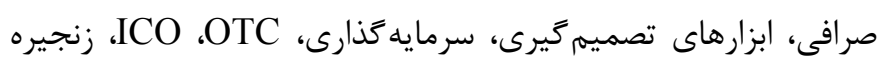

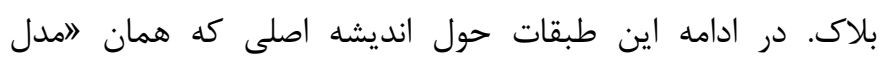

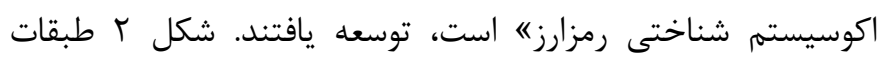

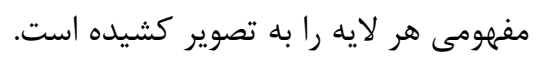

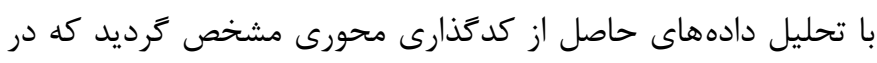

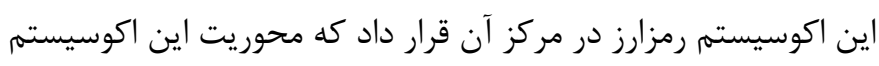


ديخر عناصر هر لايه با عناصر ساير لايهها نيز مرتبط خواهد بود بنابراين كليه عناصر با يكديكر در ارتباط هستند و عدم حضور يك عنصر كل

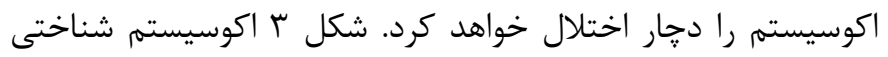
رمزارز را نشان مى دهد. جهت ارزيابى نهايى مدل توسعه يافته، مدل نهايى به تاييد دو نفر از خبركان قرار كرفت.
بايد به گونه درستى در كنار يكديخر قرار گيرند و با يكديگر در تعامل باشند تا بتواند قابليتهاى اشاره شده را ايجاد نمايد.

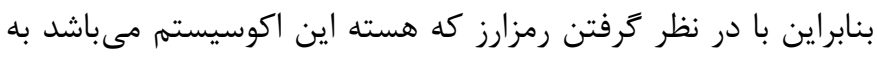

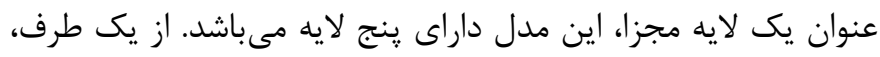

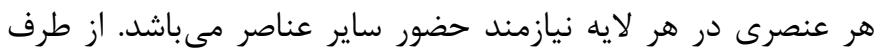

جدول ا. نتيجه كدكذارى محورى لايههاى اكوسيستم شناختى رمزارز

\section{شاهد}

خريد رمزارز جهت ذخيره (H))، خريد و نكَهدارى رمزارز به عنوان دارايى داراى ارزش مانند دلار (Hr) خريد و فروش رمزارز جهت سوداكرى (WI)، خريد در زمان كاهش قيمت و فروش در زمان افزايش قيمت رمزارز (Wr)، سوداكرى رمزارز

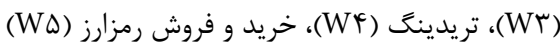
تبديل رمزارزها به يكديگر (UI)، معاوضه رمزارز با فيات يا بالعكس (UI) كاوش (KI)، كاووش و تاييد تراكنش (Kr)

شاهد

توانايى پاسخ كويى به تغييرات اكوسيستم (BI)، ورود سريع به بازارهاى جديد (BY) ايجاد نياز در بازارهاى قديمى با استفاده از رمزارز ( (N)، توسعه كاربرى هاى جديد براى رمزارز (Nr)، توسعه محصولات و خدمات نوآورانه (NY) سرمايه كذارى هاى خطريذير (RI)، ريسك ورود به فضاى جديد تبادل (RY) آينده يُروهى (Z))، يِيشبينى آينده (Zr)، تحليل تكنيكى و بنيادى (Zr) مشاركت با مراجع قانون كذارى (MI)، مشاركت با فينتكها (MY)، ايجاد ارتباط با ساير صنايع جهت يذيرش رمزارز (MY) شاهد

ايجاد فرايندها (FI)، مشخص بودن شيوه انجام فعاليتها (FT) وجود ابزارهاى تصميم گيرى (AI)، ابزارهاى خريد و فروش (AY)، محيط امنى براى نكَهدارى رمزارزها (Ar)

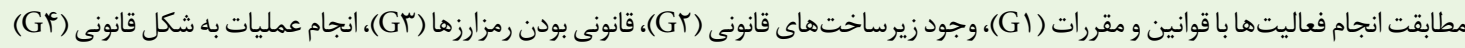
دسترسى به اينترنت (TI)، فناورى و زيرساخت هاى مورد نياز (TT)

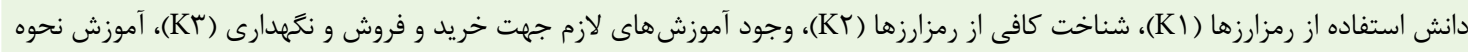
خريد و فروش و نكمدارى رمزارزها (KF)

حفظ محرمانكى اطلاعات كاربران (SI)، محيط امن براى نكَهدارى رمزارز (ST)، عدم وجود ريسك هك شدن (ST) بذيرندكان رمزارز (PY)، (PY)، إفرادى كه از رمزارز استفاده نمايند (PY)

\section{شاهد}

كيف يول سرد، كيف يول كرم، محل نكَهدارى رمزارز (WI) زنجيره بلاك (YI)، شبكه نظير به نظير (YY) (Dr) اعلام قيمت رمزارز (DI)، اعلام كارمزدها (DI) براى خريدها حجم بالا از ابزارى تحت عنوان لامقابل ميزه استفاده مىشود. ابزار معرفى رمزارز جديد و ايجاد مخاطب براى آن

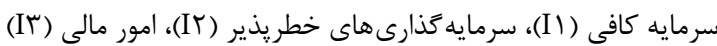

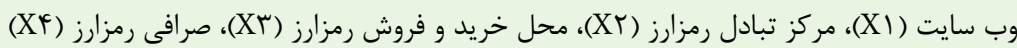

فعاليت هاى كليدى

نكهدارى (H)

تجارت (W)

تبادل (U)

كاوش (K)

قابليت ها

جابكى (B)

نوآورى (N)

(R) ريسك

تحليل (Z)

مشاركت و همكارى (M)

زيرساخت

فرايند (F)

ابزار (A)

قوانين (G)

فناورى (T)

دانش (K)

امنيت (S)

مردم (P)
كيف يول (W)

زنجيره بلاك (Y)

ابزارهاى تصميم

OTC I

ICO Y

سر مايه حذارى (I)

صرافى (X) 
رمزارز و داشتن دانش استفاده از آن، ؟) حفظ امنيت كاربران و حفظ

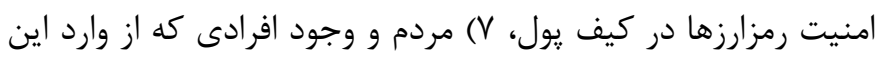

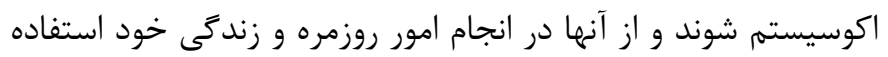
نمايند، داراى اهميت مى باشد.

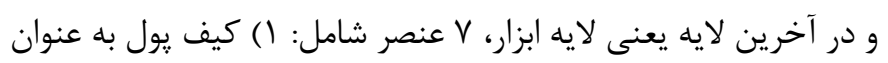

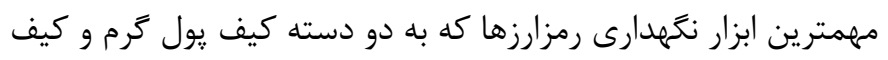

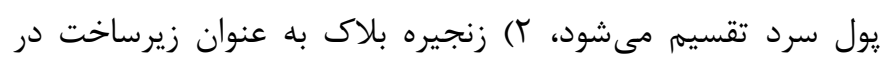

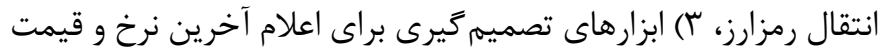
رمزارزها، اعلام به صرفهترين كارمزد براى انتقال و ....، \&) سرمايه كذارى شامل سرمايه كذارىهاى خطريذير و ابزارى براى توسعه اكوسيسته،

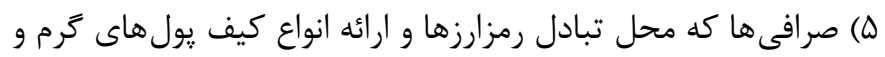

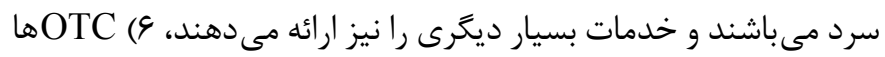

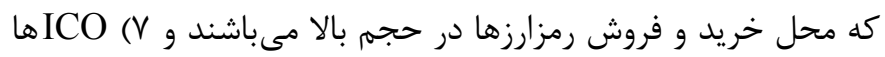

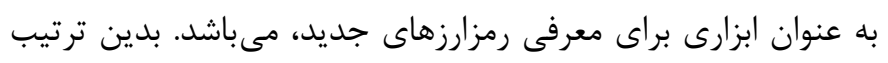

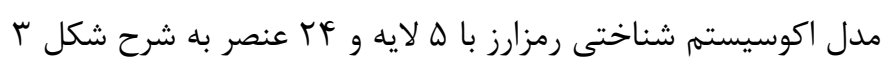

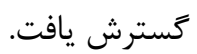
در انجام اين يزوهش محدوديت هايى به اين شرح وجود داشت: () عدم

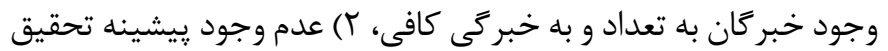

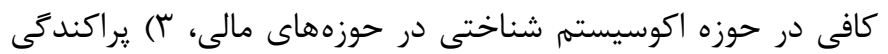
موضوعى در كدهاى استخراج شده. يُيشنهاداتى كه از سوى يزوهشكَران

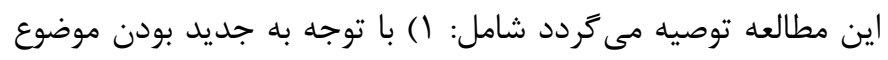

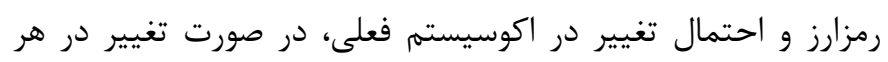

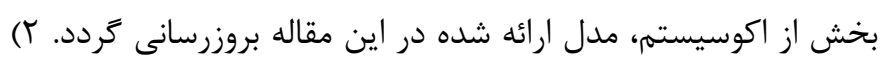

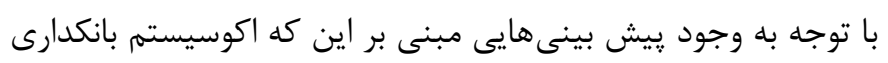

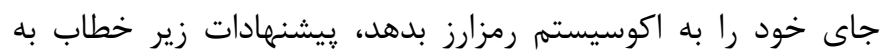
سيستم بانكى ارائه مى حكردد:

• استفاده از رمزارزها در سرمايه بانكها هماند ارزهاى خارجى

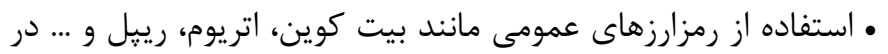

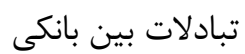
•در اختيار قرار دادن رمزارزهاى خاص به صادر كنند أنان و واردكنند براى توسعه صادرات و واردات

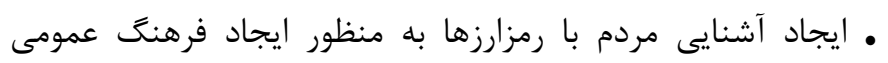

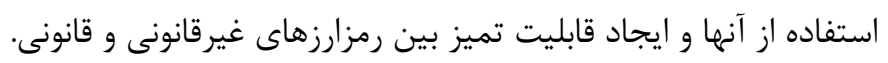
• استفاده از فناورى و زيرساخت زنجيره بلوك به عنوان بستر تبادلات

نتيجه كيرى باتوجهبهآن كهيزوهشهاى ييشينبلبخشى ازاكوسيستمرمزارزيرداختهبودند،
يزوهش هاى ييشين به بخشى از اكوسيستم رمزارز يرداخته بودند؛ براى (راى

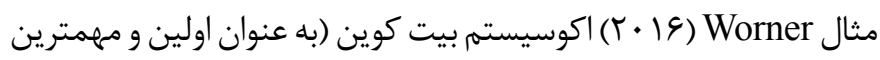

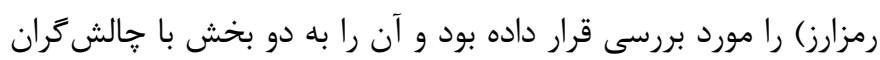

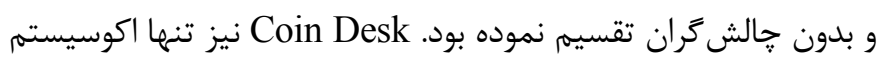

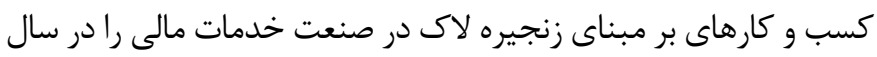

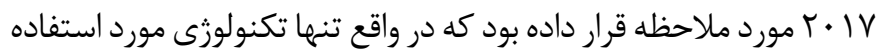
در رمزارز را در سه لايه البرنامه هاى كاربردى و راه حلها《، الخدمات و

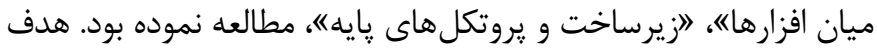

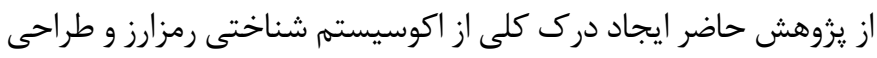

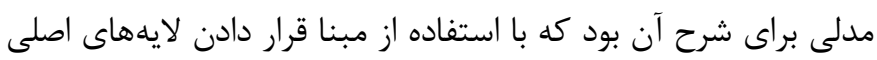

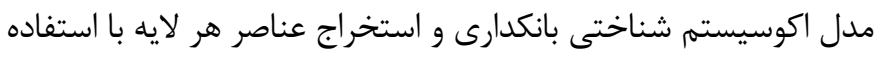
از روش داده بنياد و بررسى اكتشافى اين اكوسيستم بود. براى استخراج عناصر لايههاى اصلى از نظر متخصصين حوزه رمزارز استفاده شده است.

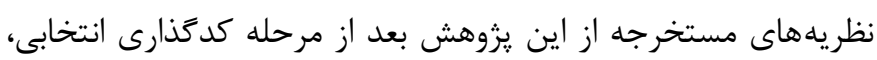

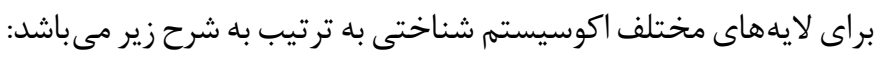
براى لايه هسته اصلى، تك عنصر رمزارز كه شامل كليه رمزارزهاى

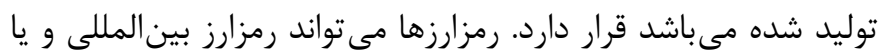

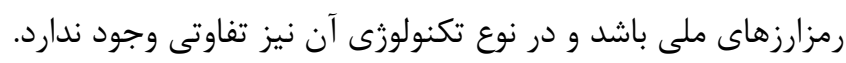

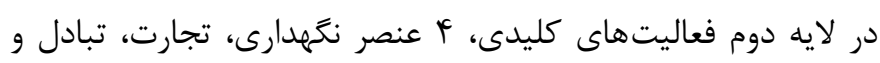

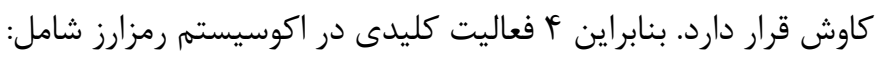

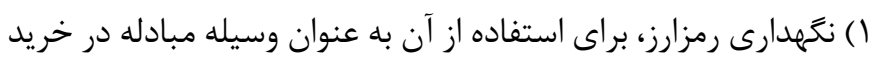

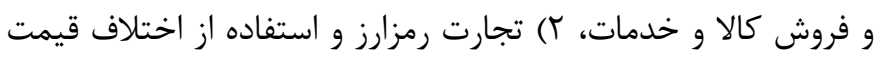

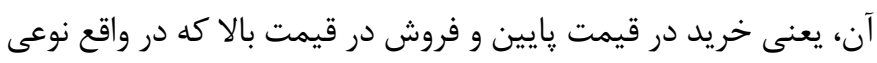
سوداترى رمزارز است، ؟) تبادل رمزارز تبديل آن به انواع ديخرى از رمزارزها و يا تبديل به فيات مى باشد، أ) كاوش و استخراج رمزارزها

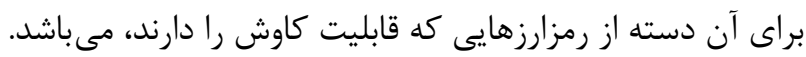

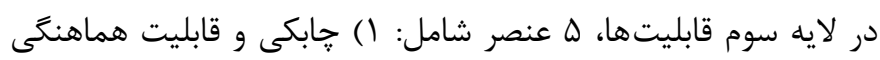

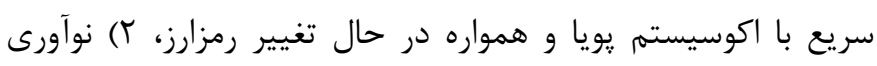

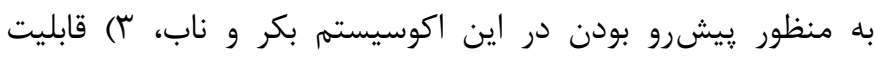

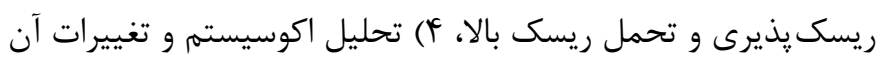

$$
\text { و مشاركت در فعاليتهاى جديد. }
$$

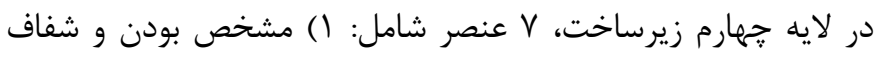
بودن فرايندهاى موجود، ؟) دسترسى به ابزارهاى مورد نياز براى انجام

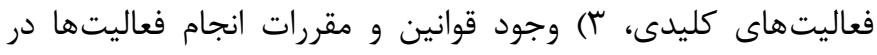

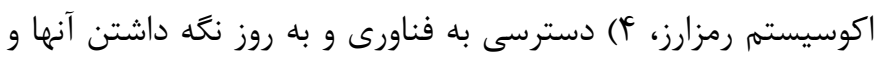

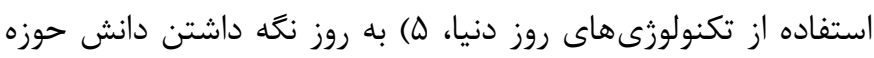




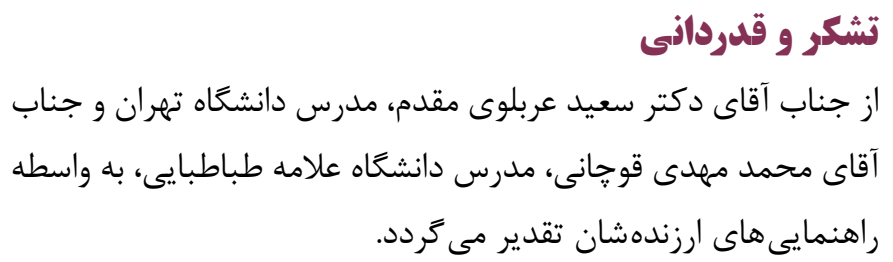

\section{References}

1. Hutchins E. Cognitive ecology. Topics in Cognitive Science. 2010;2(4):705-715.

2. Bateson G. Steps to an ecology of mind: Collected essays in anthropology, psychiatry, evolution, and epistemology. Chicago:The University of Chicago Press;2000.

3. Cicirelli F, Guerrieri A, Mercuri A, Spezzano G, Vinci A. ITEMa: A methodological approach for cognitive edge computing IoT ecosystems. Future Generation Computer Systems. 2019;92:189-197.

4. Clowes RW. Immaterial engagement: Human agency and the cognitive ecology of the internet. Phenomenology and the Cognitive Sciences. 2019;18(1):259-279.

5. Ogiela L. Cognitive information system in management science. 1st ed. London:Academic Press;2017.

6. Banking Cognitive Ecosystem, IBM's Brand Innovative Report. 2016. www.IBM.com

7. Worner D, Von Bomhard T, Schreier YP, Bilgeri D. The bitcoin ecosystem: Disruption beyond financial services?. In Twenty-Fourth European Conference on Information Systems (ECIS). 2016 June 12-15; Istanbul, Turkey;2016.

8. Beer C, Weber B. Bitcoin-the promise and limits of private innovation in monetary and payment systems. Monetary Policy and the Economy. 2015;11(4):53-66.

9. Charmaz K. Constructing grounded theory: A practical guide through qualitative analysis. Thousand Oaks, CA:Sage Publications;2006.

10. Davies D, Dodd J, Qualitative research and the question of rigor. Qualitative Health Research. 2002;12(2):279-289.

11. Kaplanov N. Nerdy money: Bitcoin, the private digital currency, and the case against its regulation. Loyola Consumer Law Review. 2012;25(1):111-174.

$$
\begin{aligned}
& \text { در يزوهش حاضر تلاش شد تادرك كلى از اكوسيستمشناختى رمزارز ايجادشده } \\
& \text { و شكاف دانشى مذكور ير شود. با توجه به رشد روزافزون در حوزه رمزارز و امكان } \\
& \text { بزرگ شدن اكوسيستم موجود و اضافه شدن بازيخرانى به آن، اين اكوسيستم } \\
& \text { مىبايست در طول زمان مجدداً مطالعه شده و مدل حاصل شده بروزرسانى شود. }
\end{aligned}
$$

12. Fung B, Halaburda H. Understanding platform-based digital currencies. Bank of Canada Review. 2014;2014(Spring):12-20. 13. Gandal N, Hamrick JT, Moore T, Oberman T. Price manipulation in the Bitcoin ecosystem. Journal of Monetary Economics. 2018;95:86-96.

14. Golafshani N. Understanding reliability and validity in qualitative research. The Qualitative Report. 2003;8(4):597-607.

15. Conte R, Castelfranchi C. Cognitive and social action. London:UCL Press;1995.

16. Kapil V. Bitcoin: A new paradigm in E-commerce. International Journal of Advanced Research in Computer and Communication Engineering. 2014;3(9):8072-8077.

17. Bobrow DG, Collins A. Representation and understanding: Studies in cognitive science. NewYork:Academic Press;1975. 18. Miller GA. The cognitive revolution: A historical perspective. Trends in Cognitive Sciences. 2003;7(3):141-144.

19. Nakamoto S. Re: Bitcoin P2P e-cash paper. The Cryptography Mailing List;2008.

20. Paquet-Clouston M, Haslhofer B, Dupont B. Ransomware payments in the bitcoin ecosystem. Journal of Cybersecurity. 2019;5(1):1-11.

21. Rogers Y, Ellis J. Distributed cognition: An alternative framework for analysing and explaining collaborative working. Journal of Information Technology. 1994;9(2):119-128.

22. Roth N. An architectural assessment of bitcoin. Procedia Computer Science. 2015;44:527-536.

23. Yermack D. Is Bitcoin a real currency? An economic appraisal. In Handbook of digital currency. Cambridge:Academic Press;2015. pp. 31-43.

24. Mason J. Qualitative researching. 3rd ed. London:Sage;2017. 